\section{International Scientific Journal Theoretical \& Applied Science}

\author{
p-ISSN: 2308-4944 (print) e-ISSN: 2409-0085 (online) \\ Year: 2017 Issue: 03 Volume: 47
}

Published: $30.03 .2017 \quad$ http://T-Science.org

SECTION 23. Agriculture. Agronomy. The technique.
Yurii Aleksandrovich Pohorukov

$\mathrm{PhD}$ in Agriculture Science,

Head of laboratory of farming crops and diversification of plant science, LLP A.I. Barayev "Scientific Production

Center for Grain Farming", Kazakhstan pohorukov_yurii@mail.ru

Artur Valerievich Verner Junior scientific fellow of lab. farming crops and diversification of plant science, LLP A.I. Barayev "Scientific Production Center for Grain Farming",

Kazakhstan,

artur-verner@mail.ru

Vladimir Vladimirovich Zabolotskih

$\mathrm{PhD}$ in Agriculture Science,

Senior scientific fellow of lab. precision agriculture, LLP A.I. Barayev "Scientific Production Center for Grain Farming", Kazakhstan, zabolotskih_vladimir@mail.ru

\title{
THE EFFECTIVE USE OF RAINFALL FOR GROWING CROP PRODUCTION
}

\begin{abstract}
The article presents the results of research on the effective use of rainfall for crop production. It is shown that on the calcareous black soils of Northern Kazakhstan it is advisable to leave plant residues on the surface of soil in the autumn period for the accumulation of a mantle of snow. Using deep mechanical tillage during the autumn will result in better absorption of defrost water. During the growing season the best option at the optimum agrophysical indicators of soil to retain moisture are the options of utilizing banded processing and No-till.

Key words: precipitation, yielding moisture, soil density, filtration, yield

Language: Russian

Citation: Pohorukov YA, Verner AV, Zabolotskih VV (2017) THE EFFECTIVE USE OF RAINFALL FOR GROWING CROP PRODUCTION. ISJ Theoretical \& Applied Science, 03 (47): 66-73.

Soi: http://s-o-i.org/1.1/TAS-03-47-15 Doi: crossef https://dx.doi.org/10.15863/TAS.2017.03.47.15

\section{ЭФФЕКТИВНОЕ ИСПОЛЬЗОВАНИЕ АТМОСФЕРНЫХ ОСАДКОВ ПРИ ВЫРАЩИВАНИИ СЕЛЬСКОХОЗЯЙСТВЕННЫХ КУЛЬТУР}

Аннотация: В статье приводятся результаты исследований по эффективному использованию атмосферных осадков при выращивании сельскохозяйственных культур. Показано, что на карбонатных черноземах Северного Казахстана целесообразно оставление на поверхности почвы растительных остатков в осенний период для накопления снежного покрова. Для лучшего впитывания тальх вод проводить осеннюю глубокую механическую обработку. При оптимальной плотности почвы можно минимизировать обработку почвы вплоть до ее отказа. В течение вегетации наилучшим вариантом при оптимальных агрофизических показателях почвы для сохранения влаги являются варианты полосовой обработки и No-till.

Ключевые слова: атмосферные осадки, продуктивная влага, плотность почвы, фильтрация, урожайность

Введение

В засушливых регионах влага является основным лимитирующим фактором получения высоких и стабильных урожаев [1, с. 396]. Атмосферные осадки являются единственным источником пополнения почвенных ресурсов (влаги). В условиях Северного Казахстана пополнение запасов почвенной влаги происходит

за счет осадков не вегетационного периода. Основным резервом почвенного увлажнения являются зимние осадки. Эффективность их использования зависит от комплекса агротехнических мероприятий, направленных на накопление и сохранение влаги в почве. и ее продуктивное использование. Этой проблеме посвящен целый ряд работ.
\end{abstract}


С 1957 г. повсеместно внедрялась система основной обработки почвы, которая предусматривала вслед за уборкой проводить глубокую вспашку почвы с выравниванием ее поверхности. При вспашке не обеспечивалось рациональное использование атмосферных осадков, особенно в острозасушливых условиях. Снежный покров со вспаханных полей сдувался в овраги и балки. Оголенная почва промерзала на значительную глубину и плохо впитывала талые воды. На вспаханных полях развивалась водная и ветровая эрозии. В результате урожаи сельскохозяйственных культур, особенно в острозасушливые годы, были низкими [2, с. 18] .

В связи с этим была разработана новая система обработки почвы - почвозащитная. Основой этой системы являлось сохранение при обработке почвы пожнивных остатков на ее поверхности. В результате на агротехнических фонах были большие запасы как общей, так и продуктивной влаги, что положительно сказалось на микробиологической активности почвы, росте и развитии растений, а также на урожае [3, с. $6 ; 4$, c. 136].

В условиях Северного Казахстана при почвозащитной обработке почвы встречаются такие явления, когда выпавший первый снег осенью тает и, переувлажнив верхние горизонты почвы, промерзает. Вследствие этого при таянии снежного покрова весной влага усваивается плохо. Одним из способов повышения водопроницаемости мерзлых почв может быть осеннее щелевание [5, с. 239]. При сравнении щелевания с плоскорезной обработкой лучшее усвоение талых вод отмечалось при нарезке щелей $[6$, с. 40$]$.

В настоящее время растет популярность ресурсосберегающих технологий возделывания сельскохозяйственных культур. Нулевые и минимальные технологии приходят в замену традиционным почвозащитным, более ёмким и затратным. Однако длительное применение Notill приводит к появлению нежелательных явлений, таких как более низкая температура поверхностного слоя почвы, в ряде случаев избыточное увлажнение почвы, а также повышенная пенетрация пахотного слоя по сравнению с классическими системами обработки почвы [7, с. 233]. В связи с этим, необходим поиск промежуточного варианта между традиционной и нулевой технологией. Полосовая обработка (strip till) или выше упомянутое щелевание, которое сходно с полосовой обработкой почвы является методом обработки, сочетающим в себе преимущества Notill и традиционной обработки. Метод полосовой обработки почвы широко распространён в ряде Европейских стран и Северной Америке. С помощью этого метода, который также известен как совершенствование No-till, почва разуплотняется в обрабатываемых полосах и увеличивается водопроницаемость и температура почвы. В обрабатываемых полосах, увеличиваются запасы почвенной влаги за счет инфильтрации дождевых и снежных осадков, что благоприятно сказывается в зонах засушливого земледелия [8, с. 169]. Полосовая обработка почвы - система применения обработки только узких полосок или зон почвы, в которые будут посеяны семена. Обработанная зона составит не более чем $25 \%$ площади поля. Полосовая обработка почвы для растениеводства является консервативной, в которой почва остается, частично, покрыта и защищена стерней предшественника, в то время как возделываемая культура посеяна, выращена и собрана в обработанных зонах почвы [9, с. 277]. Необходимо отметить основные преимущества полосовой обработки почвы: уменьшается риск возникновения ветровой и водной эрозии почвы, потому что большая часть поля остается покрытой растительными остатками в течение года; увеличивается инфильтрация воды по сравнению с полной обработкой полей; уменьшаются выбросы углерода в атмосферу и сохраняется больше органического вещества в почве. Такая обработка способствует лучшему прорастанию семян и получению дружных всходов, потому что пропашные полосы хорошо прогреваются; урожайность в этом случае находится на одном уровне либо выше по сравнению с другими системами обработки; снижает расходы, в том числе на топливо и труд, устраняя некоторые первичные и вторичные обработки [10, с. 1].

В этом ключе необходимо отметить, что возможно при полосовой обработке создаются условия для лучшего впитывания атмосферных осадков в обработанные полосы. Результаты зарубежных исследований показывают, что полосовая обработка способствует улучшению водного режима почвы. Она похожа на вспашку чизельными плугами, но при этом сохраняет влажность почвы как при нулевой обработке. При полосовой обработке порозность почвы безусловно выше, чем при No-till. Увеличивается количество пор среднего размера в верхних слоях почвы, которые очень важны для впитывания и хранения воды в прикорневой зоне [11, с. 25]. Накоплению зимних осадков способствует ненарушенный стерневой покров сельскохозяйственных культур в необрабатываемых полосках, что также влияет на эффективность использования влаги [12, с. 136].

В связи с этим целью исследований явилось изучению накопления зимних осадков, усвоению зимних и весенних осадков в почвенном профиле, 


\begin{tabular}{|c|c|c|c|c|c|c|}
\hline Impact Factor: & $\begin{array}{l}\text { ISRA (India) } \\
\text { ISI (Dubai, UAE } \\
\text { GIF (Australia) } \\
\text { JIF }\end{array}$ & $\begin{array}{r}=1.344 \\
=0.829 \\
=0.564 \\
=1.500\end{array}$ & $\begin{array}{l}\text { SIS (USA) } \\
\text { PИНЦ (Russia) } \\
\text { ESJI (KZ) } \\
\text { SJIF (Morocco) }\end{array}$ & $\begin{array}{l}=0.912 \\
=0.234 \\
=1.042 \\
=\mathbf{2 . 0 3 1}\end{array}$ & $\begin{array}{l}\text { ICV (Poland) } \\
\text { PIF (India) } \\
\text { IBI (India) }\end{array}$ & $\begin{array}{l}=6.630 \\
=1.940 \\
=4.260\end{array}$ \\
\hline
\end{tabular}

использованию почвенной влаги сельскохозяйственными культурами.

\section{Материалы и методы исследования}

Исследования проводили в 2015-2016 гг. на опытном поле Научно-производственного центра зернового хозяйства им. А.И. Бараева в лаборатории агротехники полевых культур и диверсификации растениеводства. Научнопроизводственный центр находится на $51^{\circ} 40^{\prime}$ 38.64" с.ш $71^{\circ} 00^{\prime} 58.21^{\prime \prime}$ в.д.

Главной особенностью климата является его резкая континентальность, характеризующаяся большой амплитудой колебания температуры воздуха, сухостью и незначительным количеством атмосферных осадков, с длительной зимой и коротким летом. Безморозный период сильно колеблется по годам. Средняя продолжительность безморозного периода 98, наименьшая - 73, наибольшая 168 дней.

Устойчивый снежный покров устанавливается, как правило, в первой декаде ноября и сходит в первой половине апреля. В течение зимы выпадает около 100 мм осадков с колебаниями от 60 до 120 мм. Зимой отмечается значительная ветровая деятельность. За счет зимних осадков происходит проникновение влаги на глубину 1,0-1,5 м. В весенний период отмечается быстрое нарастание тепла. Весной погода неустойчива, с частыми возвратами холодов и поздними заморозками. За апрель и май в среднем выпадает 56,0 мм осадков, однако все они расходуются на испарение. Наибольшее количество осадков, около 160 мм, выпадает в течение летнего периода. Осенью (сентябрьоктябрь) выпадает около 50 мм осадков. В условиях прохладной погоды 25-30 мм влаги накапливается в почве. Однако в годы с дождливой осенью в почве может накапливаться до 60-70 мм продуктивной влаги.

Годы исследований различались по погодным условиям. Вегетационный период 2015 года характеризовался как умеренно увлажненный, с повышенной теплообеспеченностью в начальный этап развития растений и умеренно теплый в период с июля по август. В целом сельскохозяйственный год превышал многолетние показатели, как по количеству атмосферных осадков, так и по температурному режиму. За сельскохозяйственный год выпало 415,9 мм атмосферных осадков. В осенний период (сентябрь-ноябрь) выпало 108,8 мм, за декабрь февраль - 64,5 мм, за март - май - 86,5 мм и в летние месяцы - 156,1 мм. Вегетационный период 2016 года характеризовался как умеренно увлажненный, с недостатком тепла. За сельскохозяйственный год выпало 391,3 мм осадков против 319,3 мм среднемноголетних данных. В осенний период (сентябрь-ноябрь) выпало 45,4 мм, за декабрь - февраль - 64,6 мм, за март - май - 72,1 мм и в летние месяцы - 209,2 мM.

Исследования реализованы в подзоне черноземов южных карбонатных, с содержанием гумуса 3,6 - 4,1\%. Водный режим южного карбонатного чернозема относится к непромывному типу. Полевой опыт включал два варианта основной обработки почвы (традиционная плоскорезная обработка на 25-27 см; полосовая обработка почвы с расстоянием между обрабатываемыми полосами 75 см и Notill.

В полевых опытах проводили наблюдения за состоянием снежного покрова, динамикой продуктивной влаги в почве, изменением плотности и фильтрационной способности пахотного слоя.

Научные эксперименты проведены согласно общепринятой методике полевых и лабораторных исследований.

\section{Результаты и их обсуждение}

За время проведенных исследований среднесуточная температура в зимние периоды 2014-2015 гг. и 2015-2016 гг. была выше среднемноголетних показателей. В декабре 2014 года $-12,4{ }^{\circ} \mathrm{C}$ против многолетних данных $-14,1{ }^{\circ} \mathrm{C}$, в январе 2015 года-14,7 ${ }^{\circ} \mathrm{C}$ против $-17,0{ }^{\circ} \mathrm{C}$, в феврале $-9,5{ }^{\circ} \mathrm{C}$ против $-16,6{ }^{\circ} \mathrm{C}$. В декабре 2015 года температура составляла $-6,9{ }^{\circ} \mathrm{C}$, в январе 2016 года - $-18,8{ }^{\circ} \mathrm{C}$ и в феврале $-7,8{ }^{\circ} \mathrm{C}$. Количество зимних осадков способствовало интенсивному накоплению снежного покрова. В связи с этим снежный покров интенсивно накапливался на поверхности почвы независимо от варианта обработки почвы. Мощность снежного покрова в среднем за 2 года изменялась в течение зимнего периода (рис. 1). 


\begin{tabular}{|c|c|c|c|c|c|c|}
\hline Impact Factor: & $\begin{array}{l}\text { ISRA (India) } \\
\text { ISI (Dubai, UAF } \\
\text { GIF (Australia) } \\
\text { JIF }\end{array}$ & $\begin{array}{l}=1.344 \\
=0.829 \\
=0.564 \\
=1.500\end{array}$ & $\begin{array}{l}\text { SIS (USA) } \\
\text { PИНЦ (Russia) } \\
\text { ESJI (KZ) } \\
\text { SJIF (Morocco) }\end{array}$ & $\begin{array}{l}=0.912 \\
=0.234 \\
=1.042 \\
=2.031\end{array}$ & $\begin{array}{l}\text { ICV (Poland) } \\
\text { PIF (India) } \\
\text { IBI (India) }\end{array}$ & $\begin{array}{l}=6.630 \\
=1.940 \\
=4.260\end{array}$ \\
\hline
\end{tabular}

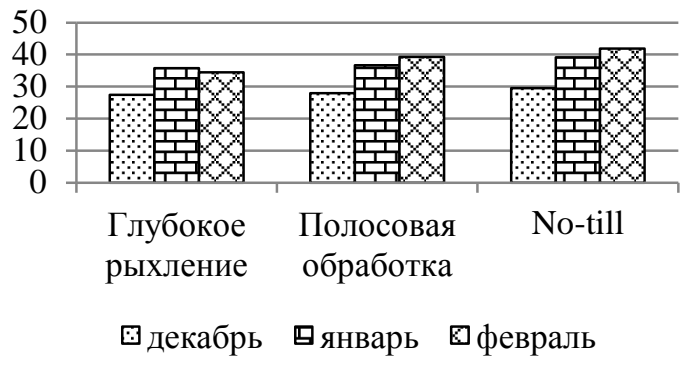

Рисунок 1 - Динамика накопления снежного покрова за период декабрь-февраль, в зависимости от агротехнического фона в среднем за 2014-2015 гг. и 2015-2016 гг., см

За годы исследования высота снежного покрова при полосовой обработке на момент снеготаяния составляла 38,7 см при плотности снежного покрова $0,29 \Gamma / \mathrm{cm}^{3}$ (табл. 1). При глубоком рыхлении почвы на 25-27 см показатель высоты снежного покрова был равен 34,6 см при плотности снега $0,31 \Gamma / \mathrm{cm}^{3}$. На варианте без обработки почвы высота снега была максимальной $(41,9$ см), это объясняется максимально полной сохранностью вертикальной стерни, которая создает дополнительную преграду при переносе снега, при этом плотность

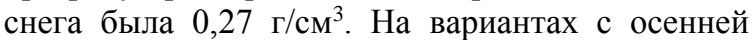
обработкой и, особенно, при глубоком рыхлении сохранность стерневого покрова меньше, что, в конечном счете, отразилось на высоте снежного покрова, при этом плотность снега выше, что выравнивает показатели полосовой обработки и варианта без обработки почвы по запасу воды в снеге.

Таблица 1

Мощность снежного покрова, плотность снега и запас воды в снеге перед началом снеготаяния, 2015 - 2016 гг.

\begin{tabular}{|c|c|c|c|c|c|c|c|c|c|}
\hline \multirow[t]{2}{*}{ Фон } & \multicolumn{3}{|c|}{$\begin{array}{c}\text { Высота снежного покрова, } \\
\text { см }\end{array}$} & \multicolumn{3}{|c|}{ 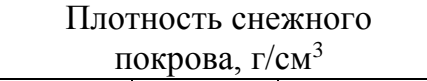 } & \multicolumn{3}{|c|}{$\begin{array}{c}\text { Запас воды в снеге, } \\
\text { мм }\end{array}$} \\
\hline & 2015 г. & 2016 г. & Среднее & 2015 г. & 2016 г. & среднее & 2015 г. & 2016 г. & среднее \\
\hline $\begin{array}{l}\text { Глубокое } \\
\text { рыхление }\end{array}$ & 30,8 & 38,5 & 34,6 & 0,31 & 0,31 & 0,31 & 94,4 & 119,3 & 106,8 \\
\hline $\begin{array}{l}\text { Полосовая } \\
\text { обработка }\end{array}$ & 34,8 & 42,7 & 38,7 & 0,30 & 0,28 & 0,29 & 104,7 & 119,6 & 112,1 \\
\hline No-till & 38,2 & 45,7 & 41,9 & 0,28 & 0,27 & 0,27 & 109,0 & 123,4 & 116,2 \\
\hline
\end{tabular}

В среднем за годы исследования запасы воды в снежном покрове на момент снеготаяния при полосовой обработке почвы составили 112,1 мм, что выше на 5,3 мм варианта с глубоким рыхлением почвы на 25-27 см и ниже на 4,1 мм варианта No-till. Запасы воды в снеге различались незначительно вследствие выпадения атмосферных осадков выше нормы и резких перепадов температуры, что позволило эффективно закрепляться снежному покрову на поверхности независимо от обработки.

При равных запасах влаги в метровом слое почвы в течение двух лет независимо от обработки почвы, перед установлением отрицательных температур в осенний период и накоплением запасов воды в снеге в пределах 100 мм и выше, запасы продуктивной влаги в метровом слое почвы после схода снега отличались.

В 2015 году в связи с интенсивным снеготаянием запасы продуктивной влаги в метровом слое почвы увеличились незначительно (табл. 2). В 2016 году из-за невысоких запасов влаги, в осенний период на варианте No-till отмечены трещины в почве, что, также как и при проведенной качественной осенней обработке почвы, привело к хорошему впитыванию влаги в весенний период, вследствие чего запасы продуктивной влаги в метровом слое почвы после схода снега значительно увеличились. 


\begin{tabular}{|c|c|c|c|c|c|c|}
\hline Impact Factor: & $\begin{array}{l}\text { ISRA (India) } \\
\text { ISI (Dubai, UAF } \\
\text { GIF (Australia) } \\
\text { JIF }\end{array}$ & $\begin{array}{l}=1.344 \\
=0.829 \\
=0.564 \\
=1.500\end{array}$ & $\begin{array}{l}\text { SIS (USA) } \\
\text { PИНЦ (Russia) } \\
\text { ESJI (KZ) } \\
\text { SJIF (Morocco) }\end{array}$ & $\begin{array}{l}=0.912 \\
=0.234 \\
=1.042 \\
=2.031\end{array}$ & $\begin{array}{l}\text { ICV (Poland) } \\
\text { PIF (India) } \\
\text { IBI (India) }\end{array}$ & $\begin{array}{l}=6.630 \\
=1.940 \\
=4.260\end{array}$ \\
\hline
\end{tabular}

Таблица 2

Запасы продуктивной влаги в метровом слое почвы в период установления отрицательных температур и схода снега с учетом запасов воды в снеге, мм

\begin{tabular}{|c|c|c|c|c|c|c|c|c|}
\hline \multirow{2}{*}{ Фон } & \multicolumn{2}{|c|}{ Уход в зиму } & \multicolumn{2}{c|}{ Запас воды в снеге } & \multicolumn{2}{c|}{ Сход снега } & \multicolumn{2}{c|}{$\begin{array}{c}+/- \\
\text { от ухода в зиму до } \\
\text { схода снега }\end{array}$} \\
\cline { 2 - 10 } & $2015 г$. & $2016 г$ & $2015 г$. & $2016 г$. & $2015 г$. & $2016 г$. & $2015 г$. & $2016 г$. \\
\hline $\begin{array}{c}\text { Глубокое } \\
\text { рыхление }\end{array}$ & 88,3 & 16,2 & 94,4 & 119,3 & 111,0 & 150,4 & $+22,7$ & $+134,2$ \\
\hline $\begin{array}{c}\text { Полосная } \\
\text { обработка }\end{array}$ & 85,5 & 18,7 & 104,7 & 119,6 & 103,7 & 148,9 & $+18,2$ & $+130,2$ \\
\hline No-till & 79,8 & 19,4 & 109,0 & 123,4 & 82,3 & 150,8 & $+2,5$ & $+131,4$ \\
\hline
\end{tabular}

В среднем за два года исследования запасы продуктивной влаги при глубоком рыхлении составили 130,7 мм, при полосовой обработке - 126,3 мм и при No-till - 116,5 мм (рис. 2).

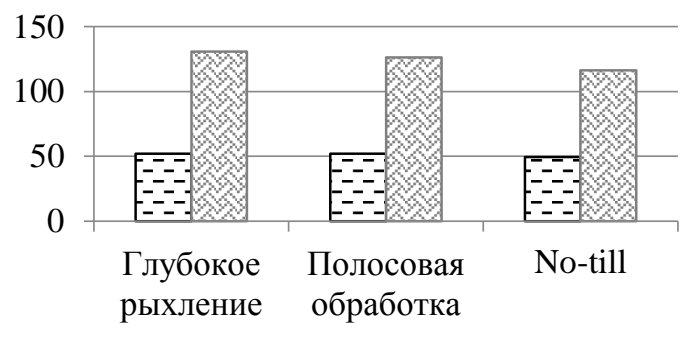

Уход в зиму 우응 снега

Рисунок 2 - Запасы продуктивной влаги в метровом слое почвы в зависимости от агротехнического фона в среднем за 2014-2015 гг. и 2015-2016 гг., см

Запасы влаги в почве к моменту посева изменялись в зависимости от агрофона и срока сева. В среднем за два года к посеву в начале второй декады мая запасы влаги снижались от момента схода снега независимо от варианта обработки почвы из-за испарения влаги и незначительного выпадения осадков в этот период. Снижение запасов влаги изменялось в зависимости от обработки почвы. Продуктивная влага в метровом слое почвы составила при глубоком рыхлении 102,9 мм, при полосовой обработке - 101,0 мм и при No-till - 92,8 мм. В наиболее выигрышном положении находились варианты с обработкой почвы. К посеву в третьей декаде мая запасы влаги были выше за счет выпадения атмосферных осадков. При этом тенденция снижения влаги при минимизации обработки сохранялась: при глубоком рыхлении 132,9 мм, при полосовой обработке - 131,9 мм и при No-till - 122,7 мм.

Одним из наиболее важных почвенных свойств при характеристике приемов обработки является плотность. Избыточное уплотнение почвы приводит к ухудшению физического состояния в целом, снижая водопроницаемость, стабильность почвенной структуры, что в итоге отражается на урожайности возделываемых культур [13, с. $133 ; 14$, с. 3$]$.

Результаты наблюдений показали, что в 2015 году к моменту посева сельскохозяйственных культур, плотность пахотного слоя почвы независимо от обработки находилась практически в одном интервале и

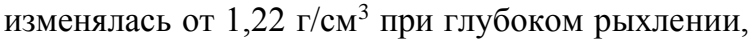

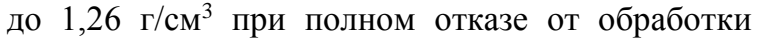
(табл. 3). Плотность почвы при полосовой обработке занимала промежуточное положение и составила 1,24 г/см ${ }^{3}$, что находится в пределах оптимальной плотности установленной для черноземов южных [15, с. 26]. В условиях 2016 года к посеву сельскохозяйственных культур

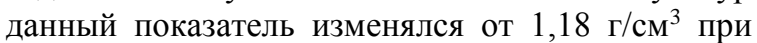
наиболее интенсивной традиционной обработке,

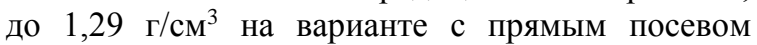
культур. Плотность почвы при полосовой обработке занимала промежуточное положение и

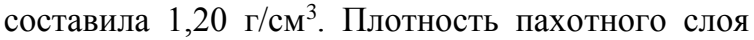
на вариантах с механическими обработками была существенно ниже в сравнении с вариантом прямого посева, что, в конечном счете, 
отразилось на фильтрационной способности

изучаемых фонов.

Таблица 3

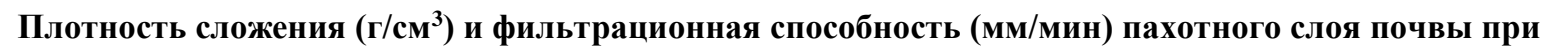
глубокой, полосовой обработке почвы и No-till перед посевом сельскохозяйственных культур
\end{abstract}

\begin{tabular}{|c|c|c|c|c|c|c|c|}
\hline \multirow[b]{2}{*}{ Фон } & \multirow[b]{2}{*}{$\begin{array}{c}\text { Слой } \\
\text { почвы }\end{array}$} & \multicolumn{2}{|c|}{$2015 \Gamma$} & \multicolumn{2}{|c|}{2016 г } & \multicolumn{2}{|c|}{ Среднее } \\
\hline & & $\begin{array}{c}\text { Плотность } \\
\text { почвы }\end{array}$ & $\begin{array}{c}\text { Фильтрация } \\
\text { почвы }\end{array}$ & $\begin{array}{c}\text { Плотность } \\
\text { почвы }\end{array}$ & $\begin{array}{c}\text { Фильтрация } \\
\text { почвы }\end{array}$ & $\begin{array}{c}\quad \text { Плот } \\
\text { ность } \\
\text { почвы }\end{array}$ & $\begin{array}{l}\text { Фильт } \\
\text { рация } \\
\text { почвы }\end{array}$ \\
\hline \multirow{4}{*}{$\begin{array}{l}\text { Глубокое } \\
\text { рыхление }\end{array}$} & $0-10$ & 1,11 & 0,36 & 1,09 & 1,44 & 1,10 & 0,90 \\
\hline & $10-20$ & 1,27 & 0,21 & 1,21 & 0,06 & 1,24 & 0,14 \\
\hline & $20-30$ & 1,27 & 0,01 & 1,22 & 0,02 & 1,25 & 0,02 \\
\hline & $0-30$ & 1,22 & 0,19 & 1,18 & 0,51 & 1,20 & 0,35 \\
\hline \multirow{4}{*}{$\begin{array}{l}\text { Полосовая } \\
\text { обработка }\end{array}$} & $0-10$ & 1,12 & 0,42 & 1,12 & 1,18 & 1,12 & 0,80 \\
\hline & $10-20$ & 1,30 & 0,09 & 1,22 & 0,16 & 1,26 & 0,13 \\
\hline & $20-30$ & 1,31 & 0,02 & 1,26 & 0,02 & 1,29 & 0,02 \\
\hline & $0-30$ & 1,24 & 0,17 & 1,20 & 0,45 & 1,22 & 0,31 \\
\hline \multirow{4}{*}{ No-till } & $0-10$ & 1,16 & 0,46 & 1,16 & 1,15 & 1,16 & 0,81 \\
\hline & $10-20$ & 1,30 & 0,02 & 1,35 & 0,08 & 1,33 & 0,05 \\
\hline & $20-30$ & 1,34 & 0,01 & 1,36 & 0,03 & 1,35 & 0,02 \\
\hline & $0-30$ & 1,26 & 0,16 & 1,29 & 0,42 & 1,28 & 0,29 \\
\hline \multicolumn{2}{|c|}{$\begin{array}{c}\mathrm{HCP}_{05} \\
\text { в слое } 0-30 \text { см }\end{array}$} & 0,06 & 0,12 & 0,08 & 0,07 & - & - \\
\hline \multicolumn{2}{|c|}{$\begin{array}{c}\text { Значение парной } \\
\text { корреляции }\end{array}$} & \multicolumn{2}{|c|}{$\left(r_{x y}\right)=-0,92$} & \multicolumn{2}{|c|}{$\left(r_{x y}\right)=-0,78$} & \multicolumn{2}{|c|}{ - } \\
\hline
\end{tabular}

Фильтрационная способность, которая показывает количество воды, просочившейся через слой почвы за определенный промежуток времени, как известно, находится в тесной зависимости от плотности почвы. На нее влияют также состояние увлажнения, качество почвенной структуры, содержание органического вещества [16, с. 4]. В весенний период 2015 года фильтрационная способность пахотного слоя имела высокую обратную корреляционную зависимость $\left(\mathrm{r}_{\mathrm{xy}}=-0,92\right)$ с плотностью почвы. Насыщенный влагой уплотненный пахотный слой имел относительно низкие показатели фильтрационной способности $(0,19$ до 0,16 мм/мин) и также как и плотность существенно не различался по изучаемым вариантам технологий.

Перед посевом сельскохозяйственных культур в 2016 году фильтрационная способность пахотного слоя изменялась в соответствии с интенсивностью обработки почвы от варианта глубокого рыхления (0,51 мм/мин) к нулевой обработке $(0,42 \mathrm{Mм} / \mathrm{Mин})$, и имела тесную обратную корреляционную связь с плотностью почвы $\left(\mathrm{r}_{\mathrm{xy}}=-0,78\right)$. Вариант полосовой технологии по показателям фильтрационной способности также занимал промежуточное положение $(0,45$ мм/мин $)$ и существенно не отличался от изучаемых вариантов. Анализ фильтрационной способности по слоям показал, что максимальной водопроницаемостью, независимо от обработки обладает поверхностный слой почв $0-10 \mathrm{~cm}$, далее, вниз по профилю фильтрационная способность резко снижается с сохранением общей тенденции. Также следует отметить более высокие показатели фильтрации горизонта 10-20см при полосовой обработке $(0,16$ мм/мин), тогда как при глубоком рыхлении и нулевой обработке значения не превышали 0,06-0,08 мм/мин.

В целом состояние плотности почвы и её фильтрационная способность перед посевом сельскохозяйственных культур на исследуемых вариантах по своим значениям не выходили за пределы оптимума, установленного для почв зоны исследований. В условиях 2016 года на вариантах с механическими обработками плотность и фильтрационная способность почвы находилась в более выигрышном положении, что отразилось и на запасах продуктивной влаги в почве.

Немаловажным показателем для сельскохозяйственных культур являются запасы продуктивной влаги в почве и в течение вегетации. Наиболее благоприятные условия по влагообеспеченности должны складываться в критические периоды растений. Например, у яровой пшеницы это фаза от выхода в трубку до колошения, у подсолнечника и гороха бутонизация-цветение и т.д. 
На примере подсолнечника отметим важность запасов продуктивной влаги в почве в фазу цветения. Подсолнечник отличается высокой потребностью к влаге, его транспирационный коэффициент 470-550, но одновременно он и засухоустойчив. Расход воды от общего потребления за вегетацию по фазам составляет: $20-22 \%$ до образования корзинок, 60$62 \%$ до конца цветения, 18-20\% до созревания.

При равном выпадении атмосферных осадков от момента посева до фазы цветения подсолнечника $(184,8$ мм в 2015 г. и 198,3 мм в 2016 г.) запасы продуктивной влаги в метровом слое почвы были различные в зависимости от изучаемых вариантов. В среднем за два года проведения исследований запасы влаги при глубоком рыхлении составили 31,8 мм, при полосовой обработке - 47,7 мм и при No-till 42,8 мм. Отмечено, что при минимизации обработки почвы к фазе цветения сохранялось больше продуктивной влаги в метровом слое почвы. Это объясняется меньшим испарением с поверхности почвы за счет ненарушенного слоя почвы или частично нарушенного и оставленных растительных остатков. При расчете использования почвенной влаги от посева до цветения подсолнечника зафиксировано, что в среднем за 2015-2016 годы наибольший расход был при глубоком рыхлении (71,1 мм), при полосовой обработке - 53,3 мм и при No-till 50,0 мм. Важно отметить и то, что в начальный период вегетации температура в посевном слое почвы при полосовой обработке, там, где и производился посев в обработанную полосу, был выше, чем между необработанными полосами и был на одном уровне с вариантом глубокого рыхления. Температура почвы между полосами находилась в одном температурном режиме с вариантом No-till. Температура почвы менялась в зависимости от среднесуточной температуры воздуха. Если устанавливалась низкая среднесуточная температура воздуха, то температура в полосе резко реагировала на смену температуры и снижалась до определенного уровня, а между полосами температура почвы реагировала на смену температурного режима плавно. Что также доказывает меньшее испарение влаги с поверхности почвы за счет оставления растительных остатков.

В конечном результате это отразилось и на получении урожайности маслосемян подсолнечника. Наибольшие показатели урожайности в среднем за два года исследования были получены по полосовой обработке и No-till (рис. 3).

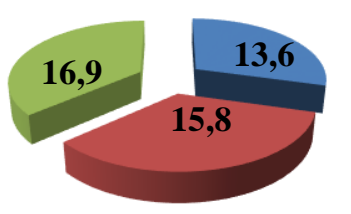

\author{
- Глубокое рыхление \\ - Полосовая обработка \\ No-till
}

\title{
Рисунок 3 - Урожайность маслосемян подсолнечника в зависимости от агротехнического фона в среднем за 2015-2016 гг., ц/га
}

\begin{abstract}
Заключение
Таким образом, на карбонатных черноземах Северного Казахстана для эффективного использования атмосферных осадков при выращивании сельскохозяйственных культур целесообразно оставление на поверхности почвы растительных остатков в осенний период для накопления снежного покрова. Для лучшего
\end{abstract}

впитывания талых вод проводить осеннюю глубокую механическую обработку. При оптимальной плотности почвы минимизировать обработку почвы вплоть до полного отказа от нее. При оптимальных агрофизических показателях почвы лучшими для сохранения влаги являются варианты полосовой обработки и No-till. 


\begin{tabular}{l|lrl|l|ll} 
& ISRA (India) & $=\mathbf{1 . 3 4 4}$ & SIS (USA) & $=\mathbf{0 . 9 1 2}$ & ICV (Poland) & $=\mathbf{6 . 6 3 0}$ \\
Impact Factor: & ISI (Dubai, UAE) $=\mathbf{0 . 8 2 9}$ & PUHU (Russia) $=\mathbf{0 . 2 3 4}$ & PIF (India) & $=\mathbf{1 . 9 4 0}$ \\
& GIF (Australia) & $\mathbf{0 . 5 6 4}$ & ESJI (KZ) & $=\mathbf{1 . 0 4 2}$ & IBI (India) & $=\mathbf{4 . 2 6 0}$
\end{tabular}

\section{References:}

1. Holmov V, Yushkevich L (2006) Intensifikaciia i resursosberezhenie $\mathrm{v}$ zemledelii lesostepi Zapadnoi Sibiri. - Omsk: FGOU VPO OmGAU, 2006. - 396 p.

2. Semenov V (1973) Priemy osnovnoi obrabotki pochvy pod iarovuyu pshenicu $\mathrm{v}$ usloviiakh stepi Yugo-zapada Orenburgskoy oblasti. Celinograd, 1973, Avtoref. diss. ... kand. s.-h. nauk. $-18 \mathrm{p}$.

3. Folmer $\mathrm{N}$ (1975) Vodnii rezhim pochvy i urozhai pshenicy $\mathrm{v}$ zavisimosti ot priemov obrabotki ziabi // Sibirskii vestnik s.-h. nauki. №3. - pp. 6-14.

4. Bakaev N (1975) Pochvennaia vlaga i urozhai. - Alma-Ata, 1975. - 136 p.

5. Kolmakov P, Nesterenko A (1981) Minimalnaia obrabotka pochvy. - M.: Kolos, 1981, pod red. Baraeva AI. - 239 p.

6. Vasko I (1986) Shchelevanie pochvy v Severnom Kazakhstane // Zemledelie. - №2. pp. 40-41.

7. Mark A, Mahdi Al-Kaisi (2005) Strip-tilla-ge effect on seedbed soil temperature and other soil physical properties // Soil \& Til-lage Research. - № 80. - pp. 233-249.

8. Celik A, Altikat S (2010) Effects of Various Strip Widths and Tractor Forward Speeds in Strip Tillage on Soil Physical Properties and Yield of Silage Corn // Journal of Agricultural Sciences. - № 16. - pp. 169-179.

9. Morrison J (2013) Strip tillage for "no-till" row crop production // Jr. Applied En-gineering in Agriculture. - № 18(3). - pp. 277-284.
10. Nowatzki J, Endres G, DeJong-Hughes J, Dwight A (2011) Strip Till for Field // Crop Production. - North Dakota State University, 2011. - pp. 1-8.

11. Petersen M (2013) Coming Back To The Benefits Of Strip-Till And Pores In The Near Surface // Strip-Till Farmer. - № 9. - pp. 25 29.

12. Katfort H, Angadi S, Macconkey B (2006) Upravlenie sternei, microclimatom, urozhainostiyu i effektivnostiyu ispolzovaniia vody pri vyrashchivanii rapsa $\mathrm{v}$ poluzasushlivykh usloviiakh kanadskikh prerii // Trudy konferecii NT-CA Agrosoyuz. Dnepropetrovsk, 2006. - pp. 136-147.

13. Esteve J, Imeson A, Jarman R, Barberis R, Rydell B, Sanchez V, Vandekerckhove L (2004) Pressures and drivers causing soil erosion // Official Publications of the European Communities. - Luxembourg, 2004. - pp. 133149.

14. Bronick C, Lal R (2005) Soil structure and management: a review // Geoderma. - №124. pp. 3-22.

15. Vasiliev A, Revut I (1965) Plotnost pochvy, optimalnaia dlia rosta selskokhoziaistvennykh rastenii na yuzhnikh karbonatnykh chernozemakh Celinogradskoi oblasti // Cb. tr. po agronomicheskoi fizike. - Leningrad, 1965. - pp. 26-35.

16. Strudley M, Green T, Ascough J (2008) Tillage effects on soil hydraulic properties in space and time // Soil Tillage Res. - № 99(1). - pp. 4-48. 